\title{
Cryptanalysis of a Multiple Server Smart Card based Authentication Scheme
}

\author{
Kwang Cheul Shin \\ Division of Industrial Management Engineering, Sungkyul University, \\ Sungkyul University-Ro 53, Anyang 8 dong, Manan-gu, Anyang-si, Gyeonggi-do \\ 14097, Korea \\ skcskc12@sungkyul.ac.kr
}

\begin{abstract}
The design of the remote user authentication scheme for access to the service server is a very important issue in a multi-server environment. In particular, it is essential for mutual authentication and key agreement process between the user and the server. Proposed so far many schemes are focused to increase safety, reduce the communication time and calculation cost. On the other hand, there is a limit to overcome a variety of attacks. In recent years, Jain et al's proposed the authentication scheme, such as mutual authentication and session key establishment, smart card-based multi-server authentication scheme to withstand a variety of attacks. In this paper, I analyze that Jain et al'.s scheme is not secure against user impersonation attack, man-in-the-middle attack, DoS attack, reply attack etc.
\end{abstract}

Keywords: Smart card, Impersonation attack. Mutual authentication, man-in-themiddle attack

\section{Introduction}

Today, many network services are needed to authenticate the user without regard to location and time. Mainly, user authentication is used in online games, on-line shopping, on-line reservation by the application server. Authentication requires a pre-registered in order to prevent the non-authorized access to the server. Users are required to register previously. Traditional single-server authentication method is used for convenience of password authentication system by a number of web services.

The server has a user identifier and registers the user's password to the verification table for confirmation [1-4].

If the traditional password authentication method is applied to a multi-server environment, the user performs the registration procedure many times and results in a high overhead at the registration center and the network. Each network user has to remember the ID of different identifiers and corresponding password, when the user must remember each time the login to a variety of remote server. This is a problem that the management of secret information is shared between the participants.

Therefore, in the multi-server environment that it is difficult to apply the conventional authentication scheme, because it must be registered several times in different remote servers stores a different ID and password. In addition, the traditional password-based remote user authentication schemes are still easily broken by simple dictionary attacks due to the low entropy of password and the secret information stored in smart card that it could be extracted by physically monitoring power consumption [5].

To eliminate such problem, a password authentication scheme has been proposed base upon smart card. Smart card is tamper resistant integrated circuit card with memory and processor capable of performing computations. In this direction, many attractive authentication schemes have been proposed using smart cards during the last decade. 
A remote user authentication scheme based on symmetric key cryptosystem of Juang[6] was proposed in 2004. But his scheme was found susceptible to the insider attack.

In 2008, Tsai [7] proposed authentication scheme without using verification table based on hash function and smart card. A common feature in most of conventional multiserver authentication scheme is as follows. The user used of the fixed identifier. Therefore, adversary may collect partial authentication information. Adversary is identifies the same user and obtains transmission information to specify the target of a variety of attacks.

2009, Liao et al's [8] proposed a dynamic remote user ID authentication scheme for anonymous users, as well as using only one-way hash function in a multi-server environment in order to avoid a hazard. But Hsiang et al's [9] pointed out that Liao et al's scheme is vulnerable to insider attacks, spoofing attack, server forgery attack, registration center forgery attacks. and they proposed an improved scheme.

In 2011, Sood et al's [10] has pointed out that Hsiang et al's scheme is not secure.

They found that the Hsiang et al's scheme is vulnerable to replay attacks, spoofing attacks, smart card stolen attacks, password changes attack. and they are proposed new scheme to prevent their anonymity and several other attacks. However, Sood et al's scheme is possible impersonation attack as a legitimate user logged into the system when the smart card is lost.

In 2012, Tsaur et al's scheme [11] proposed a mutual authentication and key agreement scheme in a multi-server environment and in 2013, Xu et al's[12] proposed a scheme that can dynamically change the user identifier of each session. However, when user using the services server, there is a problem that user must be re-registered again.

In 2014, Jain et al'.s[13] proposed an efficient and robust multi-server authentication scheme using smart card. Security of this scheme depends upon cryptographic one-way hash function. Users should be able to access all of the resources in the server once registered in a multi-server environment. Mutual authentication and key agreement process is essential between user and server. And it must be able to withstand a variety of attacks that occurred by the adversary.

In this paper, I analysis that Jain et al'.s scheme is not secure against a server impersonation attack, user impersonation attack, man-in-the-middle eavesdrop attack, smart card stolen attack. The rest of the paper is organized as follows : Section 2 reviews the Jain et al'.s scheme. In section 3, I show how to attack Jain et al'.s scheme. Finally, I make a conclusion in section 4 .

\section{Review of Jain et al.'s Authentication Scheme}

This section reviews a user authentication scheme proposed by Jain et al[13]. There are three communication parties in Jain et al's scheme: User i, Registration Center(under RC), Service Application Server S. This scheme is composed of four phases : registration phase, login phase, authentication-key agreement phase, and password change phase. I describe each phase in detail in 2.1-2.4, and Table 1 shows the notations used in the remainder of the paper.

\subsection{Registration Phase}

This phase is divided into two sub-phase: Server Registration phase and User Registration phase(as shown in Fig. 1). 
Table 1. Notation and Description

\begin{tabular}{|c|c|}
\hline Notation & Description \\
\hline$R C$ & Registration Center \\
\hline $\mathrm{U}_{\mathrm{i}}$ & $\mathrm{i}^{\text {th }}$ remote user \\
\hline $\mathrm{ID}_{\mathrm{i}}$ & Identity of user $\mathrm{i}$ \\
\hline $\mathrm{pw} \mathrm{w}_{\mathrm{i}}$ & Password of user $\mathrm{i}$ \\
\hline $\mathrm{h}(\cdot)$ & An one-way hash function \\
\hline $\mathrm{S}_{\mathrm{j}}$ & $\mathrm{j}^{\text {th }}$ authentication server $(1 \leq \mathrm{j} \leq \mathrm{n})$ \\
\hline $\mathrm{SID}_{\mathrm{j}}$ & Identity of user $\mathrm{S}_{\mathrm{j}}$ \\
\hline $\mathrm{x}$ & Secret key of Registration Center \\
\hline $\mathrm{d}$ & Secret number of Registration Center \\
\hline$\|$ & Concatenation operation \\
\hline$\oplus$ & XOR operation \\
\hline$\rightarrow$ & Insecure channel \\
\hline$\cdots>$ & Secure channel \\
\hline
\end{tabular}

\subsubsection{Server Registration Phase}

In this phase, while application server $S_{j}$ want to become an authorized server. $S_{j}$ select $\mathrm{SID}_{\mathrm{j}}$ and submits it to RC over a secure channel. Upon receiving the registration request from $\mathrm{S}_{\mathrm{j}}, \mathrm{RC}$ computes the server secret parameter $\mathrm{SS}_{\mathrm{j}}=\mathrm{h}\left(\mathrm{SID}_{\mathrm{j}} \| \mathrm{h}(\mathrm{x})\right) \oplus \mathrm{h}(\mathrm{d})$ and sends $\left.<\mathrm{SS}_{\mathrm{j}}, \mathrm{h}(\mathrm{d})\right\rangle$ to $\mathrm{S}_{\mathrm{j}}$ through a secure channel.

The authorized server uses the $\mathrm{SS}_{\mathrm{j}}$ and $\mathrm{h}(\mathrm{d})$ to check the user's legitimacy in authentication phase.

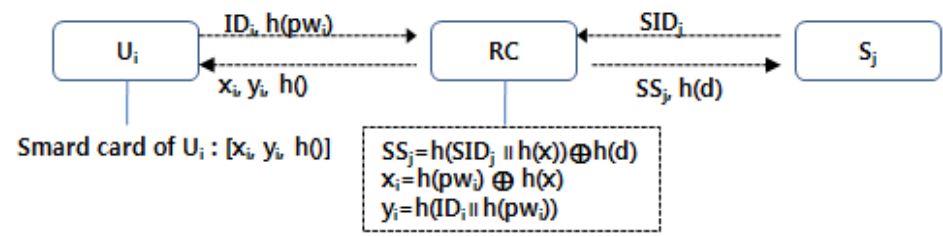

Figure 1. User and Server Registration Phase

\subsubsection{User Registration Phase}

The registration phase of Jain et al's scheme is described in Fig 1. User i needs to perform the user registration phase with the registration center using a secure channel.

$\mathrm{U}_{\mathrm{i}}$ selects $\mathrm{ID}_{\mathrm{i}}$ and $\mathrm{pw}_{\mathrm{i}}$, compute $\mathrm{h}\left(\mathrm{pw}_{\mathrm{i}}\right)$ and submits $\left\langle\mathrm{ID}_{\mathrm{i}}, \mathrm{h}\left(\mathrm{pw}_{\mathrm{i}}\right)\right\rangle$ to $\mathrm{RC}$ over a secure channel. Once the registration request is received, $R C$ computes $x i=h\left(\mathrm{pw}_{\mathrm{i}}\right) \oplus \mathrm{h}(\mathrm{x})$, $\mathrm{yi}=\mathrm{h}\left(\mathrm{ID}_{\mathrm{i}} \| \mathrm{h}\left(\mathrm{pw}_{\mathrm{i}}\right)\right)$ and issues a smart card over secure channel to $\mathrm{U}_{\mathrm{i}}$ by storing $\left\langle\mathrm{x}_{\mathrm{i}}, \mathrm{y}_{\mathrm{i}}\right.$, $h()>$ into smart card memory.

\subsection{Login Phase}

The Login and Authentication phase for the proposed scheme are described in Fig 2. In this phase, $\mathrm{U}_{\mathrm{i}}$ inserts the smart card to the card reader and keys in $\operatorname{ID}_{\mathrm{i}}$ and $\mathrm{pw}_{\mathrm{i}}{ }^{\prime}$.

The smart card computes $\mathrm{y}_{\mathrm{i}}^{\prime}=\mathrm{h}\left(\mathrm{ID}_{\mathrm{i}} \| \mathrm{h}\left(\mathrm{pw}_{\mathrm{i}} \mathrm{i}^{\prime}\right)\right)$ and verifies computed $\mathrm{y}_{\mathrm{i}}^{\prime}$ equals stored $\mathrm{y}_{\mathrm{i}}$ or not. If not, the user terminates the session. If true, reader generates a random number nonce $\mathrm{N}_{1}$, the smart card computes the following :

$$
\begin{aligned}
& \mathrm{a}_{\mathrm{i}}=\mathrm{x}_{\mathrm{i}} \oplus \mathrm{h}\left(\mathrm{pw}_{\mathrm{i}}\right) \\
& \mathrm{b}_{\mathrm{i}}=\mathrm{h}\left(\operatorname{SID}_{\mathrm{j}} \| \text { ai }\right) \\
& \mathrm{c}_{\mathrm{i}}=\mathrm{h}\left(\mathrm{b}_{\mathrm{i}} \| \mathrm{N}_{1}\right)
\end{aligned}
$$


And $\mathrm{U}_{\mathrm{i}}$ sends the login request $<\mathrm{ID}_{\mathrm{i}}, \mathrm{SID}_{\mathrm{j}}, \mathrm{N}_{1}, \mathrm{c}_{\mathrm{i}}>$ to $\mathrm{S}_{\mathrm{j}}$.

\subsection{Authentication Phase}

Upon receiving the login requests $\left\langle\mathrm{ID}_{\mathrm{i}}, \mathrm{SID}_{\mathrm{j}}, \mathrm{N}_{1}, \mathrm{c}_{\mathrm{i}}\right\rangle$. $\mathrm{S}_{\mathrm{j}}$ first checks the validity of $\mathrm{ID}_{\mathrm{i}}$ to accept/reject the login request. If true, $S_{j}$ computes $c_{i}^{\prime}=h\left(\left(S_{j} \oplus h(d)\right) \| N_{1}\right)$ and then checks whether computed $c_{i}^{\prime}$ equals received $c_{i}$ or not. If it holds, $S_{j}$ generates a nonce $\mathrm{N}_{2}$, the $S_{j}$ computes the following :

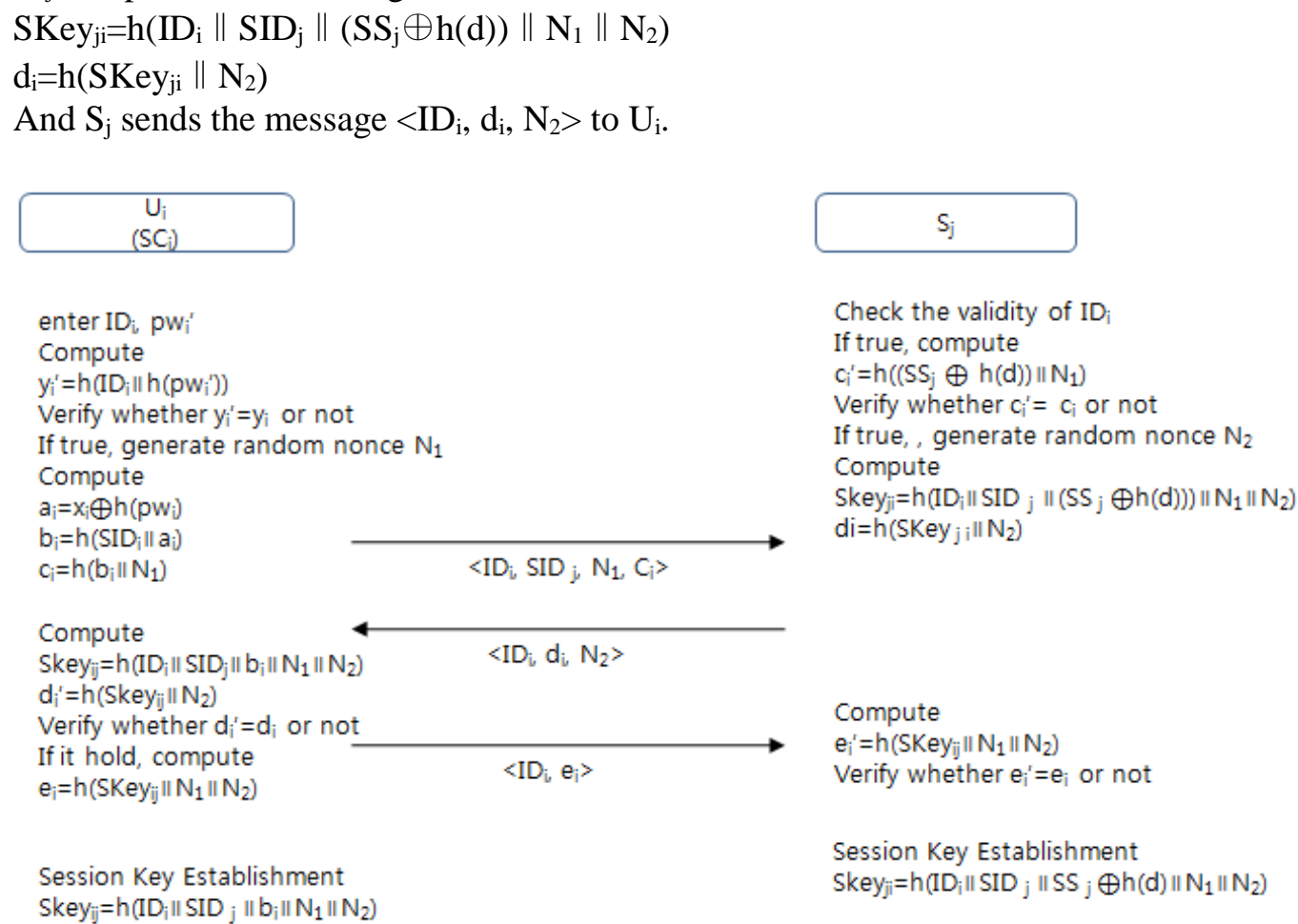

Figure 2. Login and Authentication Phase

As it described in Figure 2, after getting the message $\left\langle\mathrm{ID}_{\mathrm{i}}, \mathrm{d}_{\mathrm{i}}, \mathrm{N}_{2}>\right.$ from $\mathrm{S}_{\mathrm{j}}, \mathrm{U}_{\mathrm{i}}$ computes the following :

$\operatorname{SKey}_{\mathrm{ij}}=\mathrm{h}\left(\mathrm{ID}_{\mathrm{i}}\left\|\operatorname{SID}_{\mathrm{j}}\right\| \mathrm{b}_{\mathrm{i}}\left\|\mathrm{N}_{1}\right\| \mathrm{N}_{2}\right)$

$\mathrm{d}_{\mathrm{i}}=\mathrm{h}\left(\mathrm{SKey}_{\mathrm{ij}} \| \mathrm{N}_{2}\right)$

And checks whether the computed $d_{i}$ equals received $d_{i}$ or not. If it holds, $S_{j}$ is authentic otherwise terminate the session.

Subsequently, $\mathrm{U}_{\mathrm{i}}$ computes $\mathrm{e}_{\mathrm{i}}=\mathrm{h}\left(\mathrm{SKey}_{\mathrm{ij}}\left\|\mathrm{N}_{1}\right\| \mathrm{N}_{2}\right)$ and send $\left\langle\mathrm{ID}_{\mathrm{i}}\right.$, $\left.\mathrm{e}_{\mathrm{i}}\right\rangle$ to $\mathrm{S}_{\mathrm{j}}$. Once the message $\left\langle\mathrm{ID}_{\mathrm{i}}, \mathrm{e}_{\mathrm{i}}\right\rangle$ is received, $\mathrm{S}_{\mathrm{j}}$ computes $\mathrm{e}_{\mathrm{i}}=\mathrm{h}\left(\mathrm{SKey} \mathrm{y}_{\mathrm{ji}}\left\|\mathrm{N}_{1}\right\| \mathrm{N}_{2}\right)$ and checks whether computed ei equals received $e_{i}$ or not. If it holds, mutual authentication is achieved. Both the parties agree upon a common shared session key. The session key SKey $\mathrm{ij}_{\mathrm{ij}}$ is generated by the user $\mathrm{i}$ and the session key SKey $\mathrm{y}_{\mathrm{ji}}$ generated by the Server $\mathrm{j}$.

$\mathrm{SKey}_{\mathrm{ij}}=\mathrm{h}\left(\mathrm{ID}_{\mathrm{i}}\left\|\mathrm{SID}_{\mathrm{j}}\right\|\right.$ bi $\left.\left\|\mathrm{N}_{1}\right\| \mathrm{N}_{2}\right)$

$\operatorname{SKey}_{\mathrm{ji}}=\mathrm{h}\left(\mathrm{ID}_{\mathrm{i}}\left\|\mathrm{SID}_{\mathrm{j}}\right\|\left(\mathrm{SS}_{\mathrm{j}} \oplus \mathrm{h}(\mathrm{d})\right)\left\|\mathrm{N}_{1}\right\| \mathrm{N}_{2}\right)$.

\subsection{Password Change Phase}

The proposed password change phase is executed when the user i wants to update his password. In this phase, The user i can easily change his password without any assistance from the registration center. Ui insert the smart card to the card reader and keys in $\mathrm{ID}_{\mathrm{i}}$ and pwi'. After this, the smart card computes $y_{i}^{\prime}=h\left(I D_{i} \| h\left(p w_{i}^{\prime}\right)\right)$ and verifies whether 
computed $\mathrm{y}_{\mathrm{i}}^{\prime}$ equals stored $\mathrm{y}_{\mathrm{i}}$ or not. If true, $\mathrm{U}_{\mathrm{i}}$ enters a new password $\mathrm{pw}_{\mathrm{inew}}$. The smart card computes $\mathrm{x}_{\text {inew }}=\mathrm{x}_{\mathrm{i}} \oplus \mathrm{h}\left(\mathrm{pw}_{\mathrm{i}}\right) \oplus \mathrm{h}\left(\mathrm{pw}_{\text {inew }}\right), \mathrm{y}_{\text {inew }}=\mathrm{h}\left(\mathrm{ID}_{\mathrm{i}} \| \mathrm{h}\left(\mathrm{pw}_{\text {inew }}\right)\right)$ and stores $\mathrm{x}_{\text {inew }}, \mathrm{y}_{\text {inew }}$ instead of $x_{i}, y_{i}$ respectively in the smart card memory.

\section{Security Analysis of Jain et al.' Scheme}

In this section, I analyze the security of Jain et al'.s scheme. In Jain et al'.s scheme, they claimed as follows: their scheme provides security against server impersonation attack, user impersonation attack, reflection and parallel session attacks, replay attack, insider attack, password guessing attack, stolen verifier attack and smart card loss attack.

Unfortunately, I found that their scheme still has a many vulnerabilities. Any registered but malicious user can derive the session key between any user and server by eavesdropping their communication information in public channel. Also, this scheme cannot checks the freshness of login message, so it is use that the malicious user sends the previous message to the server. Therefore, malicious user can success the reply attack and DoS attacks.

\subsection{User impersonation attack}

User $\mathrm{i}$ send the login message $\left\langle\mathrm{ID}_{\mathrm{i}}, \mathrm{SID}_{\mathrm{j}}, \mathrm{N}_{1}, \mathrm{c}_{\mathrm{i}}>\right.$ to the server $\mathrm{j}$ in order to use the server service. Then user A is a legitimate registered user malicious. Malicious user A intercepts the login message $\left\langle\mathrm{ID}_{\mathrm{i}}, \mathrm{SID}_{\mathrm{j}}, \mathrm{N}_{1}, \mathrm{c}_{\mathrm{i}}\right\rangle$, and he/she can completely spoofing the server $\mathrm{j}$.

Malicious users A have $\mathrm{x}_{\mathrm{a}}=\mathrm{h}\left(\mathrm{pw}_{\mathrm{a}}\right) \oplus \mathrm{h}(\mathrm{x}), \mathrm{y}_{\mathrm{a}}=\mathrm{h}\left(\mathrm{ID}_{\mathrm{a}} \| \mathrm{h}\left(\mathrm{pw}_{\mathrm{a}}\right)\right)$ that it is provided by registration center, and it is stored on the smart card.

Also, malicious user A has the parameters $h(x)$ derived from $x_{a}=h\left(\mathrm{pw}_{\mathrm{a}}\right) \oplus \mathrm{h}(\mathrm{x})$.

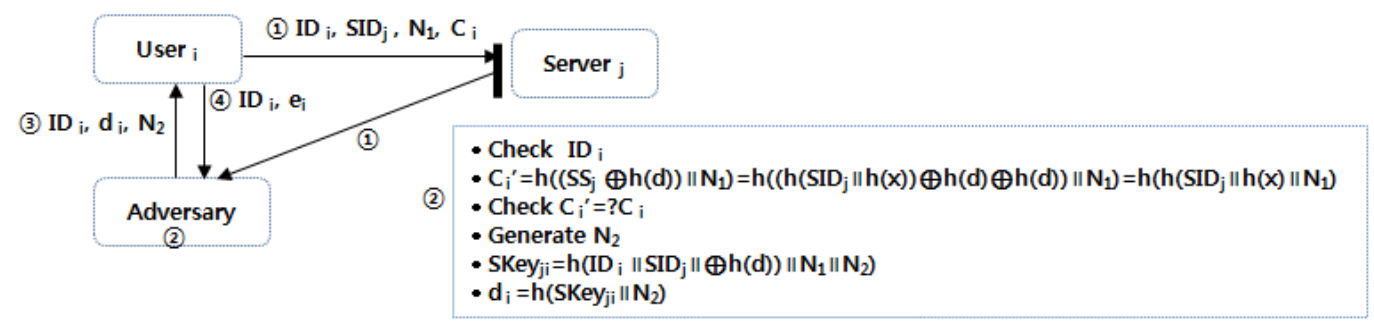

Figure 3. User impersonation attack scenario

User impersonation attack is the same as Figure 3, the scenario is as follows.

step 1 The legitimate user i sends a login message $\left\langle\mathrm{ID}_{\mathrm{i}}, \mathrm{SID}_{\mathrm{j}}, \mathrm{N}_{1}, \mathrm{c}_{\mathrm{i}}>\right.$ to server $\mathrm{j}$.

step 2 Legally registered malicious user A will intercept the login message $\left\langle\mathrm{ID}_{\mathrm{i}}, \mathrm{SID}_{\mathrm{j}}\right.$,

$\mathrm{N}_{1}, \mathrm{c}_{\mathrm{i}}>$ and the following operations.

$\mathrm{c}_{\mathrm{i}}^{\prime}=\mathrm{h}\left(\mathrm{h}\left(\operatorname{SID}_{\mathrm{j}}\|\mathrm{h}(\mathrm{x})\| \mathrm{N}_{1}\right)\right.$

$\mathrm{h}\left(\mathrm{h}\left(\mathrm{SID}_{\mathrm{j}}\|\mathrm{h}(\mathrm{x})\| \mathrm{N}_{1}\right)\right)$ is the same as $\mathrm{h}\left(\left(\mathrm{SS}_{\mathrm{j}} \oplus \mathrm{h}(\mathrm{d})\right) \| \mathrm{N}_{1}\right)$, and also $\mathrm{h}\left(\left(\mathrm{SS}_{\mathrm{j}} \oplus \mathrm{h}(\mathrm{d})\right) \| \mathrm{N}_{1}\right)$ is the same as $\mathrm{h}\left(\left(\mathrm{h}\left(\operatorname{SID}_{\mathrm{j}} \| \mathrm{h}(\mathrm{x})\right) \oplus(\mathrm{d}) \oplus(\mathrm{d})\right) \| \mathrm{N}_{1}\right)$.

Next generate a nonce $\mathrm{N}_{2}$

$\operatorname{SKey}_{\mathrm{ji}}=\mathrm{h}\left(\mathrm{ID}_{\mathrm{i}}\left\|\operatorname{SID}_{\mathrm{j}}\right\|\left(\mathrm{h}\left(\operatorname{SID}_{\mathrm{j}}\|\mathrm{h}(\mathrm{x})\| \mathrm{N}_{1} \| \mathrm{N}_{2}\right)\right.\right.$

$\mathrm{h}\left(\operatorname{ID}_{\mathrm{i}}\left\|\operatorname{SID}_{\mathrm{j}}\right\|\left(\mathrm{h}\left(\mathrm{SID}_{\mathrm{j}}\|\mathrm{h}(\mathrm{x})\| \mathrm{N}_{1} \| \mathrm{N}_{2}\right)\right.\right.$ is the same as $\mathrm{h}\left(\operatorname{ID}_{\mathrm{i}}\left\|\operatorname{SID}_{\mathrm{j}}\right\|\left(\mathrm{SS}_{\mathrm{j}} \oplus \mathrm{h}(\mathrm{d})\right)\left\|\mathrm{N}_{1}\right\| \mathrm{N}_{2}\right)$.

$\mathrm{d}_{\mathrm{i}}=\mathrm{h}\left(\mathrm{SKey}_{\mathrm{ji}} \| \mathrm{N}_{2}\right)$

step 3 The malicious user A sends $\left\langle\mathrm{ID}_{\mathrm{i}}, \mathrm{d}_{\mathrm{i}}, \mathrm{N}_{2}>\right.$ to $\mathrm{U}_{\mathrm{i}}$.

step 4 After getting the message $\left\langle\mathrm{ID}_{\mathrm{i}}, \mathrm{d}_{\mathrm{i}}, \mathrm{N}_{2}\right\rangle$ from malicious user $\mathrm{A}$, User i computes the following :

$\operatorname{SKey}_{\mathrm{ij}}=\mathrm{h}\left(\mathrm{ID}_{\mathrm{i}}\left\|\operatorname{SID}_{\mathrm{j}}\right\| \mathrm{b}_{\mathrm{i}}\left\|\mathrm{N}_{1}\right\| \mathrm{N}_{2}\right)$ 


\section{$\mathrm{d}_{\mathrm{i}}^{\prime}=\mathrm{h}\left(\mathrm{SKey}_{\mathrm{ij}} \| \mathrm{N}_{2}\right)$}

Checks whether computed $d_{i}^{\prime}$ equals received $d_{i}$ or not. If it holds, User $i$ computes $e_{i}$ the following :

$\mathrm{ei}=\mathrm{h}\left(\mathrm{SKey}_{\mathrm{ij}}\left\|\mathrm{N}_{1}\right\| \mathrm{N}_{2}\right)$

step 4 User i send $\left\langle\mathrm{ID}_{\mathrm{i}}, \mathrm{e}_{\mathrm{i}}\right\rangle$ to malicious user $\mathrm{A}$.

In this proposed Jain et al's scheme, the login request contains $\left\langle\mathrm{ID}_{\mathrm{i}}, \mathrm{SID}_{\mathrm{j}}, \mathrm{N}_{1}, \mathrm{c}_{\mathrm{i}}\right\rangle$. It contains $\quad c_{i}=h\left(b_{i} \| N_{1}\right)=h\left(h\left(\operatorname{SID}_{j} \| a_{i}\right) \| N 1\right)=h\left(h\left(\operatorname{SID}_{j} \| x_{i} \oplus h\left(p_{i}\right)\right) \| N_{1}\right)$. In order to securely perform impersonation attack, the attacker needs to guess the correct values of $\mathrm{h}\left(\mathrm{pw}_{\mathrm{i}}\right)$ and $\mathrm{h}(\mathrm{x})$. But, malicious user $\mathrm{A}$ is not necessary to use $\mathrm{h}\left(\mathrm{pw}_{\mathrm{i}}\right)$ owned by the user. The reason is as follows.

$$
\begin{aligned}
& \mathrm{c}_{\mathrm{i}}=\mathrm{h}\left(\mathrm{b}_{\mathrm{i}} \| \mathrm{N}_{\mathrm{l}}\right) \\
& =\mathrm{h}\left(\mathrm{h}\left(\operatorname{SID}_{\mathrm{j}} \| \mathrm{a}_{\mathrm{i}}\right) \| \mathrm{N}_{1} 1\right) \\
& =\mathrm{h}\left(\mathrm{h}\left(\operatorname{SID}_{\mathrm{j}} \| \mathrm{x}_{\mathrm{i}} \oplus \mathrm{h}\left(\mathrm{pw}_{\mathrm{i}}\right)\right) \| \mathrm{N}_{1}\right) \\
& =\mathrm{h}\left(\mathrm{h}\left(\operatorname{SID}_{\mathrm{j}} \| \mathrm{h}\left(\mathrm{pw}_{\mathrm{i}}\right) \oplus \mathrm{h}(\mathrm{x}) \oplus \mathrm{h}\left(\mathrm{pw}_{\mathrm{i}}\right)\right) \| \mathrm{N}_{1}\right) / / \mathrm{x}_{\mathrm{i}}=\mathrm{h}\left(\mathrm{pw}_{\mathrm{i}}\right) \oplus \mathrm{h}(\mathrm{x}) \\
& =\mathrm{h}\left(\mathrm{h}\left(\operatorname{SID}_{\mathrm{j}}\|\mathrm{h}(\mathrm{x})\| \mathrm{N}_{1}\right)\right.
\end{aligned}
$$

The malicious user A does not know the $\mathrm{h}\left(\mathrm{pw}_{\mathrm{i}}\right)$ of the user $\mathrm{i}$. But he can calculate the $\mathrm{c}_{\mathrm{i}}$. In addition, he can calculate the session key SKey $\mathrm{i}_{\mathrm{ij}}$, and he can communicate as if the server j. Therefore, Jain et al'.s scheme is vulnerable to user impersonation attack.

\subsection{Man-in-the-middle Attack}

Jain et al's scheme allows a legal malicious user to eavesdrop the communication between a user $i$ and a server $j$ and then acquire communication information that they are transmitted over the communication once the eavesdropping succeeds.

Two entities(user $i$ and server $j$ ) presume that they are successfully connected to peer side. However, they are actually connected to an intermediate entity so that the intermediate entity can collect the data sent by the user $\mathrm{i}$ and transmit the data to server $\mathrm{j}$ after manipulating it.

Man-in-the-middle attack is the same as Figure 4, the scenario is as follows.

step 1 The legitimate user i sends a login message $\left\langle\mathrm{ID}_{\mathrm{i}}, \mathrm{SID}_{\mathrm{j}}, \mathrm{N}_{1}, \mathrm{c}_{\mathrm{i}}>\right.$ to server $\mathrm{j}$.

step 2 Legally registered malicious user A will intercept the login message $<\operatorname{ID}_{\mathrm{i}}, \operatorname{SID}_{\mathrm{j}}$, $\left.\mathrm{N}_{1}, \mathrm{c}_{\mathrm{i}}\right\rangle$ and response message $\left\langle\mathrm{ID}_{\mathrm{i}}, \mathrm{d}_{\mathrm{i}}, \mathrm{N}_{2}\right\rangle$, He can calculate the session key as follows.

From the $\operatorname{SKey}_{\mathrm{ji}}=\mathrm{h}\left(\mathrm{ID}_{\mathrm{i}}\left\|\mathrm{SID}_{\mathrm{j}}\right\|\left(\mathrm{SS}_{\mathrm{j}} \oplus \mathrm{h}(\mathrm{d})\right)\left\|\mathrm{N}_{1}\right\| \mathrm{N}_{2}\right)$

$\left(\mathrm{SS}_{\mathrm{j}} \oplus \mathrm{h}(\mathrm{d})\right)$ is $\mathrm{h}\left(\mathrm{SID}_{\mathrm{j}} \| \mathrm{h}(\mathrm{x})\right)$

Using the equation $\mathrm{h}\left(\mathrm{SID}_{\mathrm{j}} \| \mathrm{h}(\mathrm{x})\right)$ and calculates a session key as follow.

$\operatorname{SKey}_{\mathrm{ji}}=\mathrm{h}\left(\mathrm{ID}_{\mathrm{i}}\left\|\operatorname{SID}_{\mathrm{j}}\right\| \mathrm{h}\left(\mathrm{SID}_{\mathrm{j}}\|\mathrm{h}(\mathrm{x})\| \mathrm{N}_{1} \| \mathrm{N}_{2}\right)\right.$ 


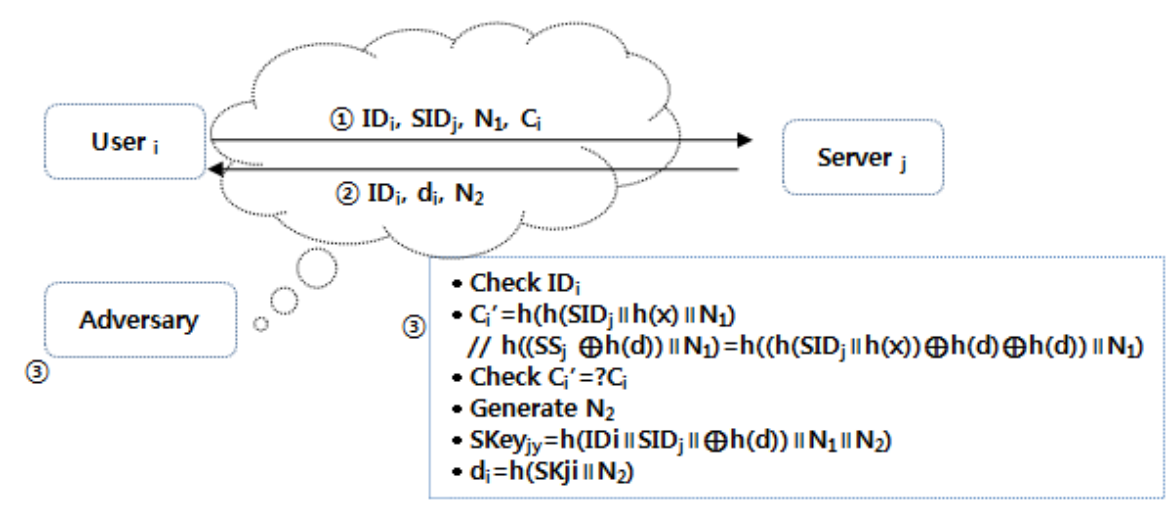

Figure 4. Man-in-the-middle Attack Scenario

Since malicious user A has intercepted the messages transmitted and received between the user and the server $\mathrm{j}$. And he/she can decrypt by the session key from all encrypted messages. Therefore, Jain et al's scheme is vulnerable to man-in-the-middle attacks.

\subsection{Denial of Service Attack}

Figure 5 describes DoS attack on Jain et al'.s scheme.

The malicious user can attempt to make the server or network resource unavailable if he use a many intercepted authentication message.

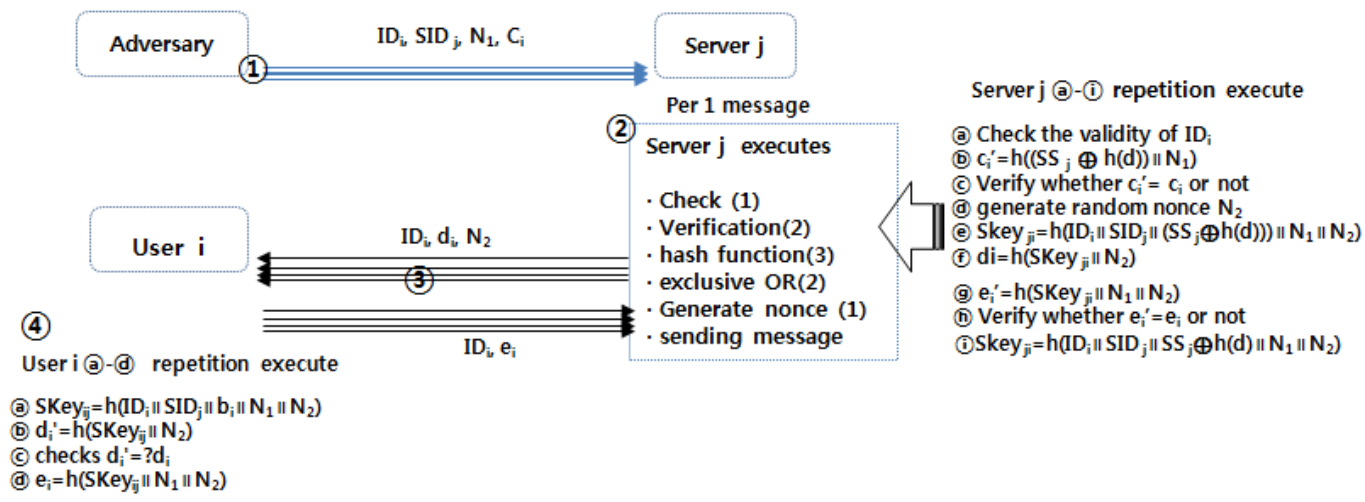

Figure 5. Denial of Service Attack Scenario

Denial of Service attack is the same as Figure 5, the scenario is as follows.

step 1 The malicious user gets the previous message (1) $<\mathrm{ID}_{\mathrm{i}}, \mathrm{SID}_{\mathrm{j}}, \mathrm{N}_{1}, \mathrm{c}_{\mathrm{i}}>$ from a legitimate user and sends that it is mass copy without modifying the login message to the server $\mathrm{j}$.

step 2 Then, the server $\mathrm{j}$ executes operation (2) and sends message (3) to the user i.

The processes of operation (2) include check the validity of $\mathrm{ID}_{\mathrm{i}}$ and verification 2 times, executing the hash function 3 times, calculating the exclusive-or operation 2 times, and generation a random nonce.

step 3 The user i repeatedly executes the message (4).

step 4 The user i send a message $\left\langle\mathrm{ID}_{\mathrm{i}}, \mathrm{e}_{\mathrm{i}}\right\rangle$ of $\mathrm{n}$ times to $\mathrm{S}_{\mathrm{j}}$.

step $5<\mathrm{ID}_{\mathrm{i}}, \mathrm{e}_{\mathrm{i}}>$ is received, $\mathrm{S}_{\mathrm{j}}$ computes $\mathrm{n}$ times the following :

$\mathrm{e}_{\mathrm{i}}^{\prime}=\mathrm{h}\left(\mathrm{SKey}_{\mathrm{ji}}\left\|\mathrm{N}_{1}\right\| \mathrm{N}_{2}\right)$

checks $\mathrm{e}_{\mathrm{i}}^{\prime}=$ ? $\mathrm{e}_{\mathrm{i}}$ 


$$
\operatorname{SKey}_{\mathrm{ij}}=\mathrm{h}\left(\operatorname{ID}_{\mathrm{i}}\left\|\mathrm{SID}_{\mathrm{j}}\right\| \mathrm{b}_{\mathrm{i}}\left\|\mathrm{N}_{1}\right\| \mathrm{N}_{2}\right)=\mathrm{h}\left(\operatorname{ID}_{\mathrm{i}}\left\|\mathrm{SID}_{\mathrm{j}}\right\|\left(\mathrm{SS}_{\mathrm{j}} \oplus \mathrm{h}(\mathrm{d})\right)\left\|\mathrm{N}_{1}\right\| \mathrm{N}_{2}\right) \text {. }
$$

In Jain et al's scheme, the server $\mathrm{j}$ does not check whether login message sent by the user $i$ is freshly created or not.

Even if the third party sends message which has been intercepted in past to the server $\mathrm{j}$, the server $\mathrm{j}$ cannot say that it is a message which has been created in past or in present. Therefore, Jain et al'.s scheme is vulnerable to Dos and replay attacks.

\subsection{Reply Attack}

The Jain et al's scheme is proposed that can prevent the replay attack. The reason for this is as follows.

Here, the replay attack will fail because the freshness of the messages transmitted in the login and authentication phases is provided by the random nonce $\mathrm{N}_{1}$ and $\mathrm{N}_{2}$. These are generated independently, and their values differ among sessions. So attackers cannot enter the system by re-sending the earlier transmitted messages to pretend to be legal users. However, same as a service denial attack of 3.3, Jain et al's scheme does not ask the question against the login message whether it is freshly created so as to determine if the message is created in real time. Furthermore, the scheme does not check if user i's parameter nonce $\mathrm{N}_{1}$ is newly created or not. Therefore, the scheme is vulnerable to a replay attack.

\subsection{No Perfect Forward Secrecy}

Perfect Forward Secrecy has characteristic that security of session key that are provided in the process of key distribution must not be compromised even if private key is exposed. According to this characteristic, new key information is mathematically not related to previous key information at all. Therefore, even in the event that someone detects previous session key, he/she cannot predict new session using the previous one.

In Jain et al's scheme, They argued as follows : The session key $\operatorname{SKey}_{\mathrm{ij}}=\mathrm{h}\left(\mathrm{ID}_{\mathrm{i}}\left\|\mathrm{SID}_{\mathrm{j}}\right\| \mathrm{b}_{\mathrm{i}}\left\|\mathrm{N}_{1}\right\| \mathrm{N}_{2}\right)=\mathrm{h}\left(\mathrm{ID}_{\mathrm{i}}\left\|\mathrm{SID}_{\mathrm{j}}\right\|\left(\mathrm{SS}_{\mathrm{j}} \oplus \mathrm{h}(\mathrm{d})\right)\left\|\mathrm{N}_{1}\right\| \mathrm{N}_{2}\right) \quad$ is associated with $\mathrm{h}\left(\mathrm{pw}_{\mathrm{i}}\right), \mathrm{h}(\mathrm{x}), \mathrm{h}(\mathrm{d})$ which are unknown to the adversary. Even though the past session key is compromised, the adversary cannot extract these parameters due to the security of one-way hash function. Moreover, it is infeasible to guess these values simultaneously. Thus, the adversary cannot obtain any further session key. However, consider the following scenario.

step 1 malicious user $A$ got $\operatorname{ID}_{\mathrm{i}}, \mathrm{SID}_{\mathrm{j}}, \mathrm{N}_{1}$ and $\mathrm{N}_{2}$ in previous public channel.

step 2 malicious user A knew common parameter $h(x)$ of user's from $x i=h\left(p_{w_{a}}\right) \oplus h(x)$

step $3 \mathrm{SKey}_{\mathrm{ji}}=\mathrm{h}\left(\mathrm{ID}_{\mathrm{i}}\left\|\mathrm{SID}_{\mathrm{j}}\right\| \mathrm{h}\left(\mathrm{SID}_{\mathrm{j}}\|\mathrm{h}(\mathrm{x})\| \mathrm{N}_{1} \| \mathrm{N}_{2}\right)\right.$

First, the malicious user got $\mathrm{ID}_{\mathrm{i}}, \mathrm{SID}_{\mathrm{j}}, \mathrm{N}_{1}$ and $\mathrm{N}_{2}$ in previous public channel between user $\mathrm{i}$ and server $\mathrm{j}$. Next, the malicious user knew common parameter $\mathrm{h}(\mathrm{x})$, so the malicious user can calculate $\mathrm{SKey}_{\mathrm{ji}}$ from $\mathrm{ID}_{\mathrm{i}}, \mathrm{SID}_{\mathrm{j}}, \mathrm{N}_{1}$ and $\mathrm{N}_{2}$.

In Jain et al'.s scheme, they claimed that $\mathrm{h}\left(\mathrm{ID}_{\mathrm{i}}\left\|\mathrm{SID}_{\mathrm{j}}\right\|\left(\mathrm{SS}_{\mathrm{j}} \oplus \mathrm{h}(\mathrm{d})\right)\left\|\mathrm{N}_{1}\right\| \mathrm{N}_{2}\right)$ is associated with $\left(\mathrm{pw}_{\mathrm{i}}\right), \mathrm{h}(\mathrm{x})$ and $\mathrm{h}(\mathrm{d})$ which are unknown to the adversary. But because $\left(\mathrm{SS}_{\mathrm{j}} \oplus \mathrm{h}(\mathrm{d})\right)$ and $\mathrm{h}\left(\mathrm{SID}_{\mathrm{j}} \| \mathrm{h}(\mathrm{x})\right.$ are equal, adversary may also be calculated the session key without knowing $\mathrm{h}(\mathrm{d}), \mathrm{h}\left(\mathrm{pw}_{\mathrm{i}}\right)$. Therefore, his schemes are vulnerable to perfect forward secrecy. 


\section{Analysis Result of Jain et al'.s Scheme}

Each users must register with the registration center to access the service server. Also, service server be registered with the registration center. Also, service servers should be registered in the registration center.

The design errors of Jain et al'.s scheme is as follows.

First, the user sends the $\mathrm{ID}_{\mathrm{i}}$ and $\mathrm{h}\left(\mathrm{pw}_{\mathrm{i}}\right)$ to the registration center. The registration center calculates $\mathrm{x}_{\mathrm{i}}, \mathrm{x}_{\mathrm{j}}, \mathrm{x}_{\mathrm{k}}, \ldots \mathrm{x}_{\mathrm{n}}$ by using its own secret key $\mathrm{x}$.

$$
\begin{aligned}
& \mathrm{x}_{\mathrm{i}}=\mathrm{h}\left(\mathrm{pw}_{\mathrm{i}}\right) \oplus \mathrm{h}(\mathrm{x}) \\
& \mathrm{x}_{\mathrm{j}}=\mathrm{h}\left(\mathrm{pw}_{\mathrm{j}}\right) \oplus \mathrm{h}(\mathrm{x}) \\
& \mathrm{x}_{\mathrm{k}}=\mathrm{h}\left(\mathrm{pw}_{\mathrm{k}}\right) \oplus \mathrm{h}(\mathrm{x}) \\
& : \\
& \mathrm{x}_{\mathrm{n}}=\mathrm{h}\left(\mathrm{pw}_{\mathrm{n}}\right) \oplus \mathrm{h}(\mathrm{x})
\end{aligned}
$$

\begin{tabular}{|c|c|c|}
\hline security components & $\begin{array}{l}\text { Analysis of } \\
\text { Jain } \text { et al'.s scheme }\end{array}$ & $\begin{array}{l}\text { Re-analysis } \\
\text { Jain et al's scheme }\end{array}$ \\
\hline Session key agreement & Yes & Yes \\
\hline Resist user impersonation attack & Yes & No \\
\hline Resist server spoofing attack & Yes & Yes \\
\hline Resist man-in-the-middle attack & $\triangle$ & No \\
\hline Resist DoS attack & $\triangle$ & No \\
\hline Resist reply attack & Yes & No \\
\hline Session key attack & Yes & No \\
\hline User anonymity & $\triangle$ & No \\
\hline Mutual authentication & Yes & Yes \\
\hline Free from maintaining verification table & Yes & Yes \\
\hline Perfect Forward Secrecy & $\triangle$ & No \\
\hline
\end{tabular}

Therefore, the legitimate all member will have the parameters $h(x)$ in common, they are using the parameter $\mathrm{h}(\mathrm{x})$ and also they can be calculated the session key of the other legitimate user.

Table 2. The Re-analysis Result of Security Properties

Second, the user should use his password when he generating the login message. However, the password was not used.

In $\mathrm{a}_{\mathrm{i}}=\mathrm{xi} \oplus \mathrm{h}\left(\mathrm{pw}_{\mathrm{i}}\right)$, user's password is used for calculation. In the long run, the calculation result turns to $\mathrm{a}_{\mathrm{i}}=\mathrm{h}(\mathrm{x})$, which means that user's password is not necessary in the computation. Therefore, the third member computes $b_{i}\left(=h\left(\operatorname{SID}_{j} \| h(x)\right)\right)$ using his/her own $\mathrm{h}(\mathrm{x})$.

Third, this is trap of $\mathrm{SS}_{\mathrm{j}}$ and $\mathrm{h}(\mathrm{d})$ submitted to servers by RC.

Since $\mathrm{SS}_{\mathrm{j}}=\mathrm{h}\left(\mathrm{SID}_{\mathrm{j}} \| \mathrm{h}(\mathrm{x})\right) \oplus \mathrm{h}(\mathrm{d})$, server $\mathrm{j}$ is not aware of $\mathrm{h}(\mathrm{x})$. Hence, server spoofing attack is secure. However, when anyone among members eavesdrops login message $c_{i}$, he/she can get solution of $\mathrm{c}_{\mathrm{i}}=\mathrm{h}\left(\mathrm{h}\left(\mathrm{SID}_{\mathrm{j}} \| \mathrm{h}(\mathrm{x})\right) \| \mathrm{N}_{1}\right)$.

At this point, an important thing is that server uses $\mathrm{h}\left(\left(\mathrm{SS}_{\mathrm{j}} \oplus \mathrm{h}(\mathrm{d})\right) \| \mathrm{N}_{1}\right)$ to calculate $\mathrm{c}_{\mathrm{i}}$ in Jain et al'.s scheme. However, since $\mathrm{h}\left(\left(\mathrm{SS}_{\mathrm{j}} \oplus \mathrm{h}(\mathrm{d})\right) \| \mathrm{N}_{1}\right)=\mathrm{h}\left(\mathrm{h}\left(\mathrm{SID}_{\mathrm{j}} \| \mathrm{h}(\mathrm{x})\right) \| \mathrm{N}_{1}\right)$, secret parameters $\mathrm{SS}_{\mathrm{j}}$ and $\mathrm{h}(\mathrm{d})$ which are only kept by server are of no use to prevent an impersonation attack attempted by the third party.

Fourth, the scheme does not provide anonymity since all information that can be used to generate session key are exposed to public channel due to user's login message $\left\langle\mathrm{ID}_{\mathrm{i}}\right.$, $\left.\mathrm{SID}_{\mathrm{j}}, \mathrm{N}_{1}, \mathrm{c}_{\mathrm{i}}\right\rangle$ and its response message $\left\langle\mathrm{ID}_{\mathrm{i}}, \mathrm{di}, \mathrm{N}_{2}\right\rangle$. Therefore, it is true that any legal member is able to calculate session key $\left(\operatorname{SKey}_{\mathrm{ji}}=\mathrm{h}\left(\operatorname{ID}_{\mathrm{i}}\left\|\operatorname{SID}_{\mathrm{j}}\right\| \mathrm{h}\left(\mathrm{SID}_{\mathrm{j}}\|\mathrm{h}(\mathrm{x})\| \mathrm{N}_{1} \| \mathrm{N}_{2}\right)\right.\right.$ ). 
Table 2 shows the security components was analyzed by Jain et al'.s, Also I show the security components by re-analyzed the Jain et al's scheme. Mark $\triangle$ is the security components could not be analyzed by Jain et al'.s.

In this paper, I was proved vulnerable to attack your impersonation attack, denial of service attacks, man-in-the-middle attacks, replay attacks, perfect forward secrecy.

\section{Conclusion}

The user shall have access to all the service servers to a single register in a multi-server environment. In particular, it is essential for mutual authentication and key agreement process between the user and the server. Authentication schemes also have to overcome a variety of attacks that occur in a public channel.

In this paper, I analyze and proved the mutual authentication and key agreement process, the ability to overcome a variety of attacks Jain et al'.s multi-server smart card based authentication scheme. I found the result of design errors by analyzing the scheme.

For this reason, My analysis reveals its inherent security vulnerabilities, such as user spoofing, man-in-the-middle attacks, no perfect forward secrecy.

\section{References}

[1] L. Lamport, "Password authentication with insecure communication", Communications of the ACM, vol. 24, no.11, (1981), pp.770-772.

[2] C. Chang, K.F. Hwang, "Some Forgery Attacks on a Remote User Authentication Scheme Using Smart Cards", Informatics Vol. 14, no. 3, (2003), pp.289-294.

[3] M.L. Das, Saxena, A. V.P. Gulati, "A dynamic ID-based remote user authentication scheme", IEEE Trans. Consum. Electron. Vol. 50, no. 2, (2003), pp.629-631.

[4] C. I. Fan, Y. C. Chan and Z. K. Zhang, "Robust remote authentication scheme with smart cards", Computers \& Security, vol. 24, , (2005), pp.619-28.

[5] T. S. Messerges, E. A. Dabbish, and R. . . Sloan, Examining smart-card security under the threat of power analysis attacks, IEEE Transactions on Computers, vol. 51, no. 5, , (2002), pp. 541-52.

[6] Juang W. S. Efficient multi-server password authenticated key agreement using smart cards. Consumer Electronics, IEEE Transactions on, 50(1), (2004), 251-.255.

[7] Tsai J. L. Efficient multi-server authentication protocol based on one-way hash function without verification table. Computers \& Security, 27(3), (2008), 115-121.

[8] Y. P. Liao and S. S. Wang, "A secure dynamic ID based remote user authentication scheme for multiserver environment," Computer Standards and Interfaces, vol. 31, no. 1, (2009), pp. 24-29.

[9] H. C. Hsiang, and W. K. Shih, Improvement of the secure dynamic ID based remote user authentication scheme for multi-server environment, Computer Standards \& Interfaces, Vol. 31, (2009), pp. 11181123 .

[10] S. K. Sood, A. K. Sarje, and K. Singh, 2011 A secure dynamic identity based authentication protocol for multi-server architecture, Journal of Network and Computer Applications, Vol. 34, No. 2, (2011), pp. 609-618.

[11] W. J. Tsaur, J. H. Li, and W. B. Lee, An efficient and secure multi-server authentication scheme with key agreement, The Journal of System and Software, Vol. 85, (2012), pp. 876-882.

[12] C. Xu, Z. Jia, F. Wen, and Y. Ma, A novel of dynamic identity based authentication scheme for multiserver environment using smart cards, International Journal of Security and Its Applications, Vol. 7, No. 4, (2013), pp. 105-118.

[13] T. Jain, S. P. Singh, An Efficient and Secure Multi-server Smart Card based Authentication Scheme, International Journal of Computer Applications, Vol. 93, No. 12, (2014), pp. 1-7. 


\section{Author}

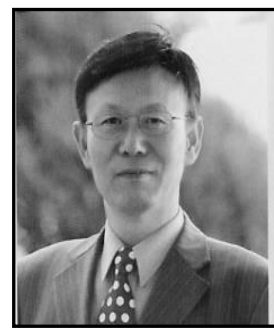

Kwang Cheul Shin Division of Industrial Management Engineering, Sungkyul University. Sungkyul University-Ro 53, Anyang 8 dong, Manan-gu, Anyang-si, Gyeonggi-do, 14097, Korea. skcskc12@sungkyul.edu.

Education \& Work experience: 2003, Ph.D. degree in Information and Communication Engineering, Sungkyunkwan University. Currently : Professor in Dept. of Industrial Management Engineering, Sungkyul University. Tel: 82-031-467-8916. 
International Journal of Security and Its Applications

Vol. 10, No. 12 (2016) 